(c) American Dairy Science Association, 2007.

\title{
Performance of Lactating Dairy Cows Fed Whole Cottonseed Coated with Gelatinized Starch plus Urea or Yeast Culture
}

\author{
K. M. Cooke, ${ }^{1}$ J. K. Bernard, ${ }^{2}$ and J. W. West \\ Department of Animal and Dairy Science, The University of Georgia, Tifton 31793-0748
}

\begin{abstract}
Thirty lactating Holstein cows were used in an 8-wk randomized design trial to test the viability of select additives included in the gelatinized corn starch coating applied to whole cottonseed (WCS) on nutrient intake and digestibility and milk yield and composition. Treatments included WCS coated with $2.5 \%$ gelatinized corn starch (control); control plus $0.5 \%$ urea; or control plus $2.0 \%$ yeast culture. The treated WCS represented $12.6 \%$ of the dietary dry matter. Cellulose intake was lower for the control coating compared with either the urea or yeast coating because of slightly lower cellulose concentrations in the control treatment. Intake of all other nutrients was similar for all treatments. Whole-tract nutrient apparent digestibility was not altered by treatment. Dry matter intake and milk yield were similar among treatments. Percentage solids-not-fat was lower for the yeast treatment compared with control, but no other differences were observed in milk composition among treatments. Efficiency of milk production (energy-corrected milk yield per unit of dry matter intake) was higher for the urea and yeast treatments compared with control because of slightly higher yield of milk fat and energy-corrected milk. No differences were observed in body weight change during the trial between treatments. Results of this trial indicate that including urea or yeast culture in the gelatinized starch coating does not change whole tract digestibility, but does improve milk production efficiency.
\end{abstract}

Key words: cottonseed, starch, urea, yeast

\section{INTRODUCTION}

Whole cottonseed (WCS) is commonly used in rations fed to lactating dairy cows as a source of energy, fiber, and protein. The high oil content of WCS makes it an attractive, energy-dense feed for animals with highenergy requirements, such as lactating dairy cattle. The

Received June 16, 2006.

Accepted August 21, 2006.

${ }^{1}$ This study was conducted as part of the postdoctoral research of K. M. Cooke.

${ }^{2}$ Corresponding author: jbernard@uga.edu high fiber concentrations provided by the lint and hulls are desirable for maintaining effective fiber levels in the diet. However, the lint makes WCS difficult to handle in mechanized feeding systems and limits its use in many commercial feed mills and dairy farms.

Coating WCS with gelatinized corn starch binds the lint and results in a free-flowing product with improved handling characteristics (Laird et al., 1997). Coating WCS with 5\% corn starch was observed to reduce fiber digestibility and milk fat percentage in lactating dairy cows (Bernard et al., 1999). However, when the coating was reduced to $2.5 \%$ corn starch, no depression in milk fat percentage occurred (Bernard, 1999). When WCS coated with gelatinized corn starch were subjected to mixed ruminal microbial fermentation, total VFA concentration and molar proportion of propionate increased whereas molar proportion of acetate decreased (Bernard et al., 1999, 2001).

One possible explanation for the slightly altered ruminal fermentation in cows fed starch-coated WCS is that the gelatinized starch coating stimulates amylolytic bacteria activity over the cellulolytic microorganisms surrounding the WCS. Reduction of cellulolytic activity could account for the decreased fiber digestion associated with feeding starch-coated WCS. Because cellulolytic microorganisms use ammonia as their primary nitrogen source, the inclusion of urea in the coating may aid in improving fiber digestion. Previous research by Bernard et al. (2003) noted that the addition of $0.5 \%$ urea in the gelatinized starch coating of WCS tended to improve ruminal NDF digestibility compared with uncoated WCS. Supplemental yeast culture has been shown to increase cellulolytic bacterial numbers (Martin and Nisbet, 1992), which could also increase fiber digestion. The objectives of this trial were to determine the effects of the addition of urea or yeast in the gelatinized cornstarch coating applied to WCS on nutrient intake and digestibility and on milk yield and composition in lactating dairy cows.

\section{MATERIALS AND METHODS}

One lot of WCS was processed through a modified gin stand to remove tags and loose lint before application of the experimental coatings (Ellis Brothers Gin, Inc., 
Center, AL). Treatments included WCS coated with 2.5\% gelatinized corn starch (WCS-C); control plus $0.5 \%$ feed-grade urea (284\% CP, DM basis) included in the coating (WCS-U); or control plus $2.0 \%$ yeast culture (Diamond V Mills XP Yeast Culture, Cedar Rapids, IA; WCS-Y). The $0.5 \%$ urea coating was based on previous research (Bernard et al., 2003) and the yeast culture rate was based on the manufacturer's recommendation to provide $56 \mathrm{~g} / \mathrm{d}$ based on the intended feeding rate. The components of the coating represented approximately $0.3 \%$ starch, $0.06 \%$ urea, and $0.25 \%$ yeast culture of the total dietary DM in the experimental diets. For each treatment, the starch was heated to $85^{\circ} \mathrm{C}$ using forced air and held at that temperature until it gelatinized. The urea or yeast culture was weighed and mixed into the heated solution before pouring over a known quantity of WCS. The treated WCS was thoroughly mixed and then dried at $120^{\circ} \mathrm{C}$ for $30 \mathrm{~min}$. After drying, WCS were allowed to cool to room temperature and then stored in tote bags for further equilibration to ambient temperature and moisture. Treated WCS were transported to the Tifton Dairy Research Center (Tifton, GA) for use in a lactation trial.

Thirty lactating Holstein cows were used in an 8-wk randomized design trial during the spring of 2004. All protocols were reviewed and approved by the University of Georgia Institute of Animal Care and Use Committee. The trial consisted of a 2 -wk standardization period followed by a 6 -wk experimental period. Cows were housed in a free-stall barn and averaged $182 \pm 40$ DIM, $38.0 \pm 7.7 \mathrm{~kg} / \mathrm{d}$ of milk yield, and $3.2 \pm 1.7$ lactations at the beginning of the trial. All cows were trained to eat behind Calan doors (American Calan Inc., Northwood, $\mathrm{NH}$ ) before beginning the trial. During the standardization period, all cows were fed the control diet containing WCS. Cows were individually fed once daily $(0800 \mathrm{~h})$ in amounts to provide approximately $10 \%$ orts for ad libitum consumption. At the end of the standardization period, cows were assigned randomly to 1 of the 3 experimental diets (WCS-C, WCS-U, or WCS-Y). Experimental diets contained $12.6 \% \mathrm{WCS}, 38.4 \%$ corn silage, $5.9 \%$ alfalfa hay, and $43.1 \%$ concentrate (steam-flaked corn, soybean meal, plus mineral-vitamin premix; DM basis, Table 1) and fed as a TMR. Amounts of TMR offered and refused were recorded daily. Cows were milked twice daily at approximately 0400 and $1500 \mathrm{~h}$ and milk yield was recorded electronically (Alpro, DeLaval, Kansas City, MO) at each milking and summed each day.

\section{Sample Collection and Analysis}

Milk samples were collected from 2 consecutive p.m. and a.m. milkings each week. Samples were shipped to
Table 1. Ingredient composition of experimental diets containing whole cottonseed coated with starch or starch plus urea or yeast culture

\begin{tabular}{lc}
\hline Ingredient & \% of DM \\
\hline Alfalfa hay & 5.93 \\
Corn silage & 38.41 \\
Cottonseed & 12.60 \\
Brewers grains, wet & 11.08 \\
Steam-flaked corn & 20.31 \\
Soybean meal & 7.70 \\
Mineral and vitamin premix ${ }^{1}$ & 3.97 \\
\hline
\end{tabular}

${ }^{1}$ Mineral and vitamin premix provided (DM basis): $25.8 \% \mathrm{CP} ; 55.2 \%$ ash; $8.59 \% \mathrm{Ca} ; 1.65 \% \mathrm{P} ; 3.58 \% \mathrm{Mg} ; 6.99 \% \mathrm{~K} ; 6.51 \% \mathrm{Na} ; 4.04 \% \mathrm{Cl}$ $0.22 \% \mathrm{~S} ; 5.88 \mathrm{ppm} \mathrm{Co} ; 339 \mathrm{ppm} \mathrm{Cu} ; 1,800$ ppm Fe; 30 ppm I; 1,038 ppm Mn; 7.5 ppm Se; 990 ppm Zn; 67,640 IU of vitamin A; 27,050 IU of vitamin D; and 425 IU of vitamin D.

Dairy Farmers of America (Knoxville, TN) for analyses of fat, protein, lactose, SNF, and MUN concentrations.

Samples of treated WCS, experimental diets, and orts were collected 3 times each week and dried in a forced air oven at $55^{\circ} \mathrm{C}$ for $48 \mathrm{~h}$. Orts were collected from all cows within each treatment and mixed before sampling. Samples were composited by week and ground to pass through a 1-mm screen using a Wiley mill (Arthur Thomas, Philadelphia, PA). Samples were analyzed for DM, CP, ash, ether extract, (AOAC, 1990), ADF, NDF, and acid detergent lignin (Ankom ${ }^{200}$ Fiber Analyzer, Ankom Technology Corp., Fairport, NY).

During wk 5 of the experimental period, fecal grab samples were collected on 4 consecutive days at 12 $\mathrm{h}$ intervals with a 2-h advancing schedule each day. Collection times were at 0500, $1700 \mathrm{~h} ; 0700,1900 \mathrm{~h}$; $0900,2100 \mathrm{~h}$; and 1000, $2300 \mathrm{~h}$, respectively, on the 4 d. Samples were composited by cow and dried in a forced-air oven at $60^{\circ} \mathrm{C}$ for $72 \mathrm{~h}$. All samples were ground to pass through a 1-mm screen using a Wiley mill and analyzed for DM, CP, ash, ether extract, ADF, $\mathrm{NDF}$, and acid detergent lignin as described previously. Fecal and corresponding diet and ort samples were also analyzed for indigestible ADF as an internal marker using the techniques described by Cochran et al. (1986) using an Ankom Daisy ${ }^{\mathrm{II}}$ Incubator (Ankom Technology, Macedon, NY).

Body weights were recorded on 2 consecutive days during the standardization period and wk 6 of the experimental period and once during wk 2 and 4 . To minimize variation, BW was recorded immediately after the p.m. milking and before animals had access to feed or water.

\section{Statistical Analysis}

Nutrient intake and digestibility measured during wk 5 and $\mathrm{BW}$ and $\mathrm{BW}$ change data were subjected to 
Table 2. Chemical composition (mean \pm SD) of whole cottonseed (WCS) coated with $2.5 \%$ gelatinized corn starch (WCS-C), $2.5 \%$ gelatinized corn starch plus $0.5 \%$ urea (WCS-U), or $2.5 \%$ gelatinized corn starch plus $2.0 \%$ yeast culture (WCS-Y)

\begin{tabular}{|c|c|c|c|}
\hline $\begin{array}{l}\text { Composition } \\
\text { of WCS }\end{array}$ & $\begin{array}{l}\text { WCS-C } \\
\text { (control) }\end{array}$ & WCS-U & WCS-Y \\
\hline \multirow[b]{2}{*}{$\mathrm{DM}$} & & $-(\%)$ & \\
\hline & $94.1 \pm 1.3$ & $94.3 \pm 1.3$ & $94.1 \pm 1.4$ \\
\hline $\mathrm{CP}$ & $17.5 \pm 0.7$ & $19.3 \pm 0.6$ & $17.7 \pm 0.9$ \\
\hline $\mathrm{NDF}$ & $50.3 \pm 1.8$ & $48.7 \pm 2.1$ & $49.4 \pm 1.3$ \\
\hline Hemicellulose & $14.6 \pm 1.4$ & $14.1 \pm 1.7$ & $14.2 \pm 2.6$ \\
\hline $\mathrm{ADF}$ & $35.7 \pm 1.2$ & $34.6 \pm 0.9$ & $35.2 \pm 2.2$ \\
\hline Cellulose & $22.5 \pm 2.5$ & $20.8 \pm 2.4$ & $20.1 \pm 3.5$ \\
\hline Acid detergent lignin & $13.2 \pm 2.3$ & $13.8 \pm 2.5$ & $15.2 \pm 2.9$ \\
\hline Ether extract & $18.4 \pm 0.7$ & $18.4 \pm 1.1$ & $18.1 \pm 1.4$ \\
\hline Ash & $3.6 \pm 0.2$ & $3.3 \pm 1.0$ & $3.7 \pm 0.2$ \\
\hline
\end{tabular}

ANOVA using PROC GLM procedures of SAS (SAS Institute, 2001). The model included cow, treatment, and error. Weekly DMI, milk yield, and composition data were subjected to analysis of covariance using the PROC MIXED procedures of SAS (SAS Institute, 2001). The model included covariate, treatment, week, treatment by week, and error. For each variable the corresponding value from the preliminary period and initial DIM were used as covariates. Cow within treatment was included as a random effect and week as a repeated effect. Contrast of control vs. urea and control vs. yeast were included in the analysis of all data.

\section{RESULTS AND DISCUSSION}

\section{Chemical Composition of WCS and TMR}

The chemical composition of the WCS treatments is presented in Table 2. The composition of the coated WCS was similar except that the CP content of WCSU was slightly higher (19.3\%) compared with WCS$\mathrm{C}$ and WCS-Y (17.5 and $17.7 \%$, respectively). This is consistent with planned differences associated with addition of urea to the coating. Experimental diets contained similar concentrations of nutrients (Table 3). The supplemental urea was calculated to increase dietary CP concentrations by approximately 0.2 percentage units. Based on the measured values, it would appear that the control diet contained slightly more $\mathrm{CP}$ than planned. Average concentration of DM, CP, and NDF for the experimental diets was 48.4, 17.9, and $38.6 \%$ of DM, respectively.

\section{Nutrient Intake and Digestibility}

Nutrient intake, corrected for orts, and apparent digestibility data measured during wk 5 are presented
Table 3. Chemical composition (mean \pm SD) of experimental diets containing whole cottonseed (WCS) coated with starch (WCS-C), starch plus urea (WCS-U), or starch plus yeast culture (WCS-Y)

\begin{tabular}{|c|c|c|c|}
\hline $\begin{array}{l}\text { Composition } \\
\text { of diets }\end{array}$ & $\begin{array}{l}\text { WCS-C } \\
\text { (control) }\end{array}$ & WCS-U & WCS-Y \\
\hline \multirow[b]{2}{*}{$\mathrm{DM}$} & & $-(\%)$ & \\
\hline & $48.7 \pm 1.6$ & $48.3 \pm 1.3$ & $48.0 \pm 1.7$ \\
\hline $\mathrm{CP}$ & $18.0 \pm 0.8$ & $18.0 \pm 0.8$ & $17.8 \pm 0.9$ \\
\hline $\mathrm{NDF}$ & $38.9 \pm 1.4$ & $39.1 \pm 2.5$ & $38.3 \pm 1.6$ \\
\hline Hemicellulose & $21.4 \pm 0.9$ & $21.1 \pm 1.3$ & $20.5 \pm 1.3$ \\
\hline $\mathrm{ADF}$ & $17.5 \pm 1.2$ & $18.0 \pm 1.7$ & $17.8 \pm 1.0$ \\
\hline Cellulose & $7.8 \pm 3.1$ & $9.3 \pm 2.8$ & $8.7 \pm 2.8$ \\
\hline Acid detergent lignin & $10.2 \pm 2.8$ & $8.3 \pm 1.9$ & $9.2 \pm 2.6$ \\
\hline Ether extract & $4.5 \pm 0.1$ & $4.7 \pm 0.6$ & $4.7 \pm 0.4$ \\
\hline Ash & $5.9 \pm 0.3$ & $5.9 \pm 0.1$ & $5.9 \pm 0.4$ \\
\hline
\end{tabular}

in Table 4. No differences were observed among treatments for DMI, which averaged $25.9 \mathrm{~kg} / \mathrm{d}$. Crude protein intake was lower $(P=0.04)$ for WCS-Y $(4.5 \mathrm{~kg} / \mathrm{d})$ compared with WCS-C $(5.0 \mathrm{~kg} / \mathrm{d})$. The lower CP intake is related to numerically lower DMI and slightly lower CP concentration in WCS-Y $(25.2 \mathrm{~kg} / \mathrm{d}$ and $17.8 \%) \mathrm{com}-$ pared with WCS-U (26.5 kg/d and 18.0\%). Cellulose intake $(1.84,2.50$, and $2.47 \mathrm{~kg} / \mathrm{d}$, respectively) was lower for WCS-C compared with WCS-U $(P=0.01)$ and WCS-Y $(P=0.01)$ primarily because of slightly lower dietary concentrations in WCS-C compared with WCSU and WCS-Y (7.8, 9.3, and 8.7\%, respectively).

Nutrient digestibility was similar among treatments (Table 4). These results are in agreement with Bernard et al. (2003) who noted no difference in total-tract nutrient digestibility in animals fed WCS coated with gelatinized starch or gelatinized starch plus urea. Ruminal fermentation characteristics in the same study noted a reduction in molar proportions of isobutyrate in diets containing urea-coated WCS, suggesting reduced fermentation of lysine.

Cellulose digestion has been shown to decrease in the presence of a rapidly fermentable carbohydrate (Stern et al., 1978) due to competition between amylolytic and cellulolytic bacteria (Martin and Nisbet, 1992). Urea provides an $\mathrm{NH}_{3}-\mathrm{N}$ source for cellulolytic microorganisms that promotes their activity to counteract the effect of starch in the coating. Although the diets fed would not be expected to be limiting in $\mathrm{N}$, the addition of urea has consistently improved the ruminal environment based on in vitro results (Bernard et al., 2001). The CP content of WCS-U was in agreement with our estimated concentration; concentrations in the coating may have been lower than that required to stimulate or optimize cellulolytic bacterial populations based on whole-tract digestibility of fiber fractions.

Digestibility of $\operatorname{ADF}(P=0.08)$ tended to be higher when cows were fed diets containing WCS-Y compared 
Table 4. Nutrient intake and apparent digestibility of lactating dairy cows fed diets containing whole cottonseed (WCS) coated with gelatinized corn starch (WCS-C), starch plus urea (WCS-U), or starch plus yeast culture (WCS-Y) ${ }^{1}$

\begin{tabular}{lrrrrrr}
\hline & WCS-C & & & & \multicolumn{2}{c}{ Contrasts $^{2}(P<)$} \\
\cline { 5 - 7 } Item & control) & WCS-U & WCS-Y & SEM & 1 & 2 \\
\hline Intake, kg/d & & & & & & \\
DM & 26.49 & 25.62 & 25.16 & 0.88 & 0.49 & 0.30 \\
CP & 5.04 & 4.73 & 4.54 & 0.16 & 0.19 & 0.04 \\
NDF & 10.05 & 10.24 & 10.01 & 0.35 & 0.71 & 0.95 \\
Hemicellulose & 5.50 & 5.64 & 5.20 & 0.19 & 0.63 & 0.26 \\
ADF & 4.54 & 4.60 & 4.82 & 0.16 & 0.81 & 0.24 \\
Cellulose & 1.84 & 2.50 & 2.47 & 0.08 & 0.01 & 0.01 \\
Ether extract & 1.25 & 1.22 & 1.20 & 0.04 & 0.67 & 0.43 \\
Apparent digestibility, \% & & & & & & \\
DM & 62.36 & 59.59 & 60.86 & 1.25 & 0.13 & 0.41 \\
CP & 67.51 & 63.12 & 63.44 & 1.81 & 0.10 & 0.13 \\
NDF & 40.50 & 38.61 & 40.71 & 1.35 & 0.33 & 0.91 \\
Hemicellulose & 53.26 & 50.97 & 50.82 & 1.94 & 0.42 & 0.38 \\
ADF & 26.57 & 24.55 & 29.82 & 1.27 & 0.29 & 0.08 \\
Cellulose & 25.39 & 32.33 & 33.19 & 2.99 & 0.19 & 0.14 \\
Ether extract & 62.00 & 72.54 & 65.93 & 4.76 & 0.13 & 0.57 \\
\hline
\end{tabular}

${ }^{1}$ Data were collected during wk 5 of the trial.

${ }^{2}$ Contrasts: 1 = WCS-C vs. WCS-U; 2 = WCS-C vs. WCS-Y.

with WCS-C (Table 4). This is in agreement with previous studies (Weidmeier et al., 1987; Erasmus et al., 1992) that noted increased $\mathrm{ADF}$ and cellulose digestion with supplemental yeast culture. Others (Williams et al., 1991; Wohlt et al., 1991) have reported little or no effect of yeast culture on diet digestibility. No other differences were observed in the apparent digestibility of other nutrients with WCS-Y.

\section{Production Response}

Dry matter intake, milk yield, and milk composition were similar among treatments (Table 5). There was a tendency for slightly higher yields of milk fat $(P=0.06)$ and ECM $(P=0.06)$ increasing the efficiency of milk production $(P=0.04)$ for cows fed WCS-U compared with WCS-C. Previous research has not demonstrated a positive response in milk fat yield when supplemental urea was included in the diet (Casper et al., 1990; Cameron et al., 1991). In vitro mixed ruminal microorganism fermentation of WCS coated with combinations of starch and urea increased butyric acid concentrations (Bernard et al., 2001), which may partially account for the slight increase in milk fat yield with WCS-U.

Concentrations of milk protein $(P=0.06)$ and $\mathrm{SNF}$ $(P=0.03)$ were lower for cows fed WCS-Y compared

Table 5. Dry matter intake, milk yield and composition of cows fed diets containing whole cottonseed (WCS) coated with starch (WCS-C), starch plus urea (WCS-U), or starch plus yeast culture (WCS-Y)

\begin{tabular}{|c|c|c|c|c|c|c|}
\hline \multirow[b]{2}{*}{ Item } & \multirow{2}{*}{$\begin{array}{l}\text { WCS-C } \\
\text { (control) }\end{array}$} & \multirow[b]{2}{*}{ WCS-U } & \multirow[b]{2}{*}{ WCS-Y } & \multirow[b]{2}{*}{ SEM } & \multicolumn{2}{|c|}{ Contrasts $^{1}(P<)$} \\
\hline & & & & & 1 & 2 \\
\hline DMI, kg/d & 26.2 & 26.5 & 25.6 & 0.56 & 0.62 & 0.48 \\
\hline Milk, kg/d & 37.4 & 38.4 & 38.2 & 1.05 & 0.50 & 0.60 \\
\hline Fat, $\%$ & 3.87 & 4.06 & 4.11 & 0.11 & 0.32 & 0.20 \\
\hline Fat, kg/d & 1.45 & 1.56 & 1.57 & 0.13 & 0.06 & 0.10 \\
\hline Protein, \% & 3.19 & 3.20 & 3.11 & 0.03 & 0.87 & 0.06 \\
\hline Protein, kg/d & 1.19 & 1.23 & 1.19 & 0.10 & 0.44 & 0.95 \\
\hline Lactose, \% & 4.89 & 4.83 & 4.84 & 0.04 & 0.30 & 0.40 \\
\hline Lactose, $\mathrm{kg} / \mathrm{d}$ & 1.75 & 1.80 & 1.78 & 0.14 & 0.48 & 0.60 \\
\hline $\mathrm{SNF}, \%$ & 8.99 & 8.92 & 8.84 & 0.04 & 0.31 & 0.03 \\
\hline SNF, kg/d & 3.20 & 3.31 & 3.24 & 0.29 & 0.44 & 0.69 \\
\hline ECM, kg/d & 39.2 & 41.2 & 41.0 & 1.02 & 0.06 & 0.10 \\
\hline MUN, mg/dL & 9.22 & 8.74 & 8.19 & 0.72 & 0.63 & 0.35 \\
\hline Efficiency $^{2}$ & 1.50 & 1.56 & 1.60 & 0.04 & 0.04 & 0.02 \\
\hline $\mathrm{SCC}$ & 268.6 & 365.2 & 311.8 & 124.0 & 0.59 & 0.81 \\
\hline Initial BW, kg & 646.2 & 637.6 & 645.7 & 17.7 & 0.74 & 0.99 \\
\hline BW gain, kg & 26.0 & 21.8 & 27.0 & 7.01 & 0.68 & 0.91 \\
\hline
\end{tabular}

${ }^{1}$ Contrasts: 1 = WCS-C vs. WCS-U; 2 = WCS-C vs. WCS-Y.

${ }^{2}$ Efficiency defined as ECM/DMI. 
with WCS-C. This decrease is due to numerically higher milk yield with WCS-Y because yield of milk protein and SNF was not different among treatments. Wohlt et al. (1991) reported lower milk protein percentage when supplemental yeast culture was included in diets fed to lactating dairy cows. Efficiency of milk production was higher $(P=0.02)$ for cows fed WCS-Y compared with WCS-C. The increase was because of a tendency for slightly higher $(P=0.10)$ yield of milk fat and ECM yield with similar DMI. Increased FCM was observed for cows supplemented with 0,10 , or $20 \mathrm{~g} / \mathrm{d}$ of yeast culture resulting in FCM yield of 37.7, 40.7, and 41.4 $\mathrm{kg} / \mathrm{d}$, respectively (Wohlt et al., 1998). The results from the current trial are consistent with previous studies (Williams et al., 1991; Wohlt et al., 1991). No other differences were observed for milk yield or milk components in animals fed WCS-Y.

\section{CONCLUSIONS}

Coating WCS with gelatinized starch or gelatinized starch plus urea or yeast did not alter nutrient intake or whole tract nutrient digestibility. Milk production efficiency was improved for both WCS-U and WCS-Y because of a tendency for improved yield of fat and ECM without any difference in DMI. These results suggest that the inclusion of urea or yeast culture in the gelatinized cornstarch coating applied to WCS could improve nutrient utilization in support of milk production.

\section{REFERENCES}

AOAC. 1990. Official Methods of Analysis. 15th ed. Association of Official Analytical Chemists Washington, DC.

Bernard, J. K. 1999. Performance of lactating dairy cows fed WCS coated with gelatinized corn starch. J. Dairy Sci. 82:1305-1313.

Bernard, J. K., M. C. Calhoun, and S. A. Martin. 1999. Effect of coating WCS on performance of lactating dairy cows. J. Dairy Sci. 82:1296-1304.
Bernard, J. K., S. A. Martin, and T. C. Wedegaertner. 2001. In vitro mixed ruminal microorganism fermentation of WCS coated with gelatinized corn starch and urea. J. Dairy Sci. 84:154-158.

Bernard, J. K., J. W. West, D. S. Trammell, A. H. Parks, and T. C. Wedegaertner. 2003. Ruminal fermentation and bacterial protein synthesis of WCS coated with combinations of gelatinized corn starch and urea. J. Dairy Sci. 86:3661-3666.

Cameron, M. R., T. H. Klusmeyer, G. L. Lynch, J. H. Clark, and D. R. Nelson. 1991. Effects of urea and starch on rumen fermentation, nutrient passage to the duodenum, and performance of cows. J. Dairy Sci. 74:1321-1336.

Casper, D. P., D. J. Schingoethe, and W. A. Eisenbeisz. 1990. Response of early lactation dairy cows fed diets varying in source of nonstructural carbohydrate and crude protein. J. Dairy Sci. 73:1039-1050.

Cochran, R. C., D. C. Adams, J. D. Wallace, and M. L. Galyean. 1986. Predicting digestibility of different diets with internal markers: Evaluation of four potential markers. J. Anim. Sci. 63:1476-1483.

Erasmus, L. J., P. M. Botha, and A. Kistner. 1992. Effect of yeast culture supplement on production, rumen fermentation, and duodenal nitrogen flow in dairy cows. J. Dairy Sci. 75:3056-3065.

Laird, W., T. C. Wedegaertner, and T. D. Valco. 1997. Coating cottonseed for improved handling characteristics. Pages 1599-1602 in Proc. Beltwide Cotton Conf., New Orleans, LA. Natl. Cotton Council. Am., Memphis, TN.

Martin, S. A., and D. J. Nisbet. 1992. Effect of direct-fed microbials on rumen microbial fermentation. J. Dairy Sci. 75:1736-1744.

SAS Institute. 2001. SAS User's Guide. Statistics, Version 8 ed. SAS Inst., Inc., Cary, NC.

Stern, M. D., H. Hoover, C. J. Sniffen, B. J. Cooker, and P. H. Knowleton. 1978. Effects of nonstructural carbohydrate, urea, and soluble protein levels on microbial protein synthesis in continuous culture of rumen contents. J. Anim. Sci. 47:944-956.

Weidmeier, R. D., M. J. Arambel, and J. L. Walters. 1987. Effects of yeast culture and Aspergillus oryzae fermentation extract on ruminal characteristics and nutrient digestibility. J. Anim. Sci. 70:2063-2068.

Williams, P. E., C. A. Tait, G. M. Innes, and C. J. Newbold. 1991. Effects of the inclusion of yeast culture (Saccharomyces cerevisiae plus growth medium) in the diet of dairy cows on milk yield and forage degradation and fermentation patterns in the rumen of steers. J. Anim. Sci. 69:3016-3026.

Wohlt, J. E., T. T. Corcione, and P. K. Zajac. 1998. Effect of yeast intake on feed intake and performance of cows fed diets based on corn silage during early lactation. J. Dairy Sci. 81:1345-1352.

Wohlt, J. E., A. D. Finkelstein, and C. H. Chung. 1991. Yeast culture to improve intake, nutrient digestibility, and performance by dairy cattle during early lactation. J. Dairy Sci. 74:1395-1400. 